\title{
Low Direct Cytotoxicity of Loxoprofen on Gastric Mucosal Cells
}

\author{
Naoki Yamakawa, Shintaro Suemasu, Ayumi Kimoto, Yasuhiro Arai, Tomoaki Ishihara, \\ Kazumi Yoкомizo, Yoshinari Oкамото, Masami Otsuka, Ken-ichiro Tanaka, and \\ Tohru Mizushima* \\ Graduate School of Medical and Pharmaceutical Sciences, Kumamoto University; Kumamoto 862-0973, Japan. \\ Received October 22, 2009; accepted December 1, 2009
}

\begin{abstract}
Pro-drugs of non-steroidal anti-inflammatory drugs (NSAIDs), such as loxoprofen are widely used for clinical purposes because they are not so harmful to the gastrointestinal mucosa. We recently showed that NSAIDs such as indomethacin and celecoxib have direct cytotoxicity (ability to induce necrosis and apoptosis in gastric mucosal cells) due to their membrane permeabilizing activities, which is involved in NSAID-induced gastric lesions. We show here that under conditions where indomethacin and celecoxib clearly induce necrosis and apoptosis, loxoprofen and its active metabolite loxoprofen- $\mathrm{OH}$, do not have such effects in primary culture of guinea pig gastric mucosal cells. Loxoprofen and loxoprofen- $\mathrm{OH}$ induced apoptosis more effectively in cultured human gastric cancer cells than in the primary culture. Loxoprofen and loxoprofen-OH exhibited much lower membrane permeabilizing activities than did indomethacin and celecoxib. We thus consider that the low direct cytotoxicity of loxoprofen observed in vitro is involved in its relative safety on production of gastric lesions in clinical situation.
\end{abstract}

Key words loxoprofen; gastric mucosal cell; membrane permeabilization; gastric lesion

Non-steroidal anti-inflammatory drugs (NSAIDs), such as indomethacin, are a useful family of therapeutics. ${ }^{1)}$ An inhibitory effect of NSAIDs on cyclooxygenase (COX) activity is responsible for their anti-inflammatory actions because COX is an enzyme essential for the synthesis of prostaglandins (PGs), such as $\mathrm{PGE}_{2}$, which have a strong capacity to induce inflammation. On the other hand, NSAID use is associated with gastrointestinal complications. ${ }^{2-4)}$

In 1991, two subtypes of COX, COX-1 and COX-2, which are responsible for the majority of COX activity at the gastrointestinal mucosa and in tissues with inflammation, respectively, were identified. ${ }^{5,6)}$ Since $\mathrm{PGE}_{2}$ has a strong protective effect on the gastrointestinal mucosa, it is reasonable to speculate that selective COX-2 inhibitors maintain anti-inflammatory activity without gastrointestinal side-effects. In fact, a greatly reduced incidence of gastroduodenal lesions has been reported for selective COX-2 inhibitors (such as celecoxib and rofecoxib). ${ }^{7-9)}$ However, a recently raised issue concerning the use of selective COX-2 inhibitors is their potential risk for cardiovascular thrombotic events..$^{10,11)}$ This may be due to the fact that prostacyclin, a potent antiaggregator of platelets and a vasodilator, is mainly produced by COX-2 in vascular endothelial cells, while thromboxane $\mathrm{A}_{2}$, a potent aggregator of platelets and a vasoconstrictor, is mainly produced by COX-1 in platelets. ${ }^{12-14)}$ Because of this concern, rofecoxib was withdrawn from the worldwide market. Therefore, NSAIDs exhibiting gastrointestinal safety, other than selective COX-2 inhibitors, are clinically important.

The inhibition of COX by NSAIDs is not the sole explanation for the gastrointestinal side-effects of NSAIDs. ${ }^{15)} \mathrm{We}$ have recently demonstrated that NSAIDs induce necrosis and apoptosis in cultured gastric mucosal cells and at gastric mucosa in a manner independent of COX inhibition. ${ }^{16-20)}$ We clearly showed that the primary target of NSAIDs for induction of necrosis and apoptosis is cytoplasmic membranes. ${ }^{16,18)}$ As for the molecular mechanism governing this apoptosis, we have proposed the following pathway. Perme- abilization of cytoplasmic membranes by NSAIDs stimulates $\mathrm{Ca}^{2+}$ influx and increases intracellular $\mathrm{Ca}^{2+}$ levels, which in turn induces the endoplasmic reticulum (ER) stress response. ${ }^{16,21,22)}$ In this response, an apoptosis-inducing transcription factor, CCAAT/enhancer-binding protein (C/EBP) homologous transcription factor (CHOP), is induced and CHOP induces expression of p53 up-regulated modulator of apoptosis (PUMA) and resulting translocation and activation of Bax, mitochondrial dysfunction, activation of caspases and apoptosis. ${ }^{1723)}$ Furthermore, we have suggested that both COX inhibition and gastric mucosal cell death are required for the formation of NSAID-induced gastric lesions in vivo. ${ }^{20,24)}$

Loxoprofen has been used clinically for a long time as a standard NSAID in Japan, and clinical studies have suggested that it is safer than other NSAIDs, such as indomethacin. ${ }^{25,26)}$ Loxoprofen is a pro-drug, which is converted (by reduction of the cyclopentanone moiety) to its active metabolite (the trans-alcohol metabolite of loxoprofen, loxoprofen-OH) by aromatic aldehyde-ketone reductase only after absorption by the gastrointestinal tract. ${ }^{27)}$ However, the direct cytotoxicity and membrane permeabilization activity of loxoprofen has not been tested. In this study, we found that loxoprofen and loxoprofen-OH have relatively lower membrane permeabilization activities and cytotoxic effects on gastric mucosal cells than other NSAIDs. Based on these observations, we consider that the low direct cytotoxicity of loxoprofen will render its use clinical safe on the gastrointestinal mucosa.

\section{MATERIALS AND METHODS}

Chemicals and Media RPMI 1640 was obtained from Nissui Pharmaceutical Co. Fetal bovine serum (FBS) and 3(4,5-dimethyl-thiazol-2-yl)-2,5-diphenyl tetrazolium bromide (MTT) were from Sigma Co. Loxoprofen and loxoprofen-OH were kindly gifted from Daiichi-Sankyo Co. Indomethacin was from Wako Co. Celecoxib was from LKT Laboratories Inc. 
Egg phosphatidylcholine (PC) was from Kanto Chemicals Co. Male guinea pigs weighing 200-300 g were purchased from Kyudo Co. The experiments and procedures described here were carried out in accordance with the Guide for the Care and Use of Laboratory Animals as adopted and promulgated by the National Institute of Health and were approved by the Animal Care Committee of Kumamoto University.

In Vitro Assay of Cytotoxicity of NSAIDs and COX-Inhibition Gastric mucosal cells were isolated from guinea pig fundic glands as described previously. ${ }^{28,29)}$ Isolated gastric mucosal cells were cultured for $12 \mathrm{~h}$ in RPMI 1640 containing $0.3 \% \mathrm{v} / \mathrm{v}$ FBS, $100 \mathrm{U} / \mathrm{ml}$ ampicillin and $100 \mu \mathrm{g} / \mathrm{ml}$ streptomycin in type-I collagen-coated plastic culture plates under the conditions of $5 \% \mathrm{CO}_{2} / 95 \%$ air and $37^{\circ} \mathrm{C}$. After removing non-adherent cells, cells attached to the plate were used. Guinea pig gastric mucosal cells prepared under these conditions were previously characterized, with the majority (about 90\%) of cells being identified as pit cells. ${ }^{28,30)}$ Human gastric adenocarcinoma (AGS) cells were cultured on plastic culture plates without collagen-coating under the same conditions.

NSAIDs were dissolved in dimethyl sulfoxide (DMSO). Cells were exposed to NSAIDs by changing the entire bathing medium.

We used MTT assay for monitoring cell viability. Cells were incubated for $2 \mathrm{~h}$ with MTT solution at a final concentration of $0.5 \mathrm{mg} / \mathrm{ml}$. Isopropanol and hydrochloric acid were added to the culture medium at final concentrations of $50 \%$ and $20 \mathrm{~mm}$, respectively. The optical density of each sample at $570 \mathrm{~nm}$ was determined spectrophotometrically using a reference wavelength of $630 \mathrm{~nm}^{31)}$

The amount of $\mathrm{PGE}_{2}$ in the medium was determined using an EIA kit (Cayman, Ann Arbor, MI, U.S.A.) according to the manufacturer's protocol.

Apoptotic DNA fragmentation was monitored as previously described. ${ }^{31)}$ Cells were collected using a rubber policeman and suspended in $20 \mu \mathrm{l}$ of lysis buffer, consisting of

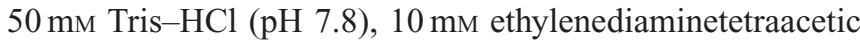
acid (EDTA), and $0.5 \%$ sodium- $N$-lauroylsarcosinate. Proteinase $\mathrm{K}$ was added to a final concentration of $1 \mathrm{mg} / \mathrm{ml}$, and the lysate was incubated at $50^{\circ} \mathrm{C}$ for $2 \mathrm{~h}$. RNaseA was then added to a final concentration of $0.5 \mathrm{mg} / \mathrm{ml}$ and incubated at $50{ }^{\circ} \mathrm{C}$ for $30 \mathrm{~min}$. These samples were analyzed by $2 \%$ agarose gel electrophoresis in the presence of $0.5 \mu \mathrm{g} / \mathrm{ml}$ ethidium bromide.

Apoptotic chromatin condensation was monitored as described previously. ${ }^{31)}$ Cells were washed with PBS, stained with $10 \mu \mathrm{g} / \mathrm{ml}$ Ho 342 and observed under a fluorescence microscope.

Membrane Permeability Assay Membrane permeability assays were performed as described previously. ${ }^{16,18,32)} \mathrm{Li}$ posomes were prepared using the reversed-phase evaporation method. Egg PC $(10 \mu \mathrm{mol}, 7.7 \mathrm{mg})$ was dissolved in chloroform/methanol $(1: 2, \mathrm{v} / \mathrm{v})$, dried, and dissolved in $1.5 \mathrm{ml}$ of diethyl ether. This was followed by the addition of $1 \mathrm{ml}$ of $100 \mathrm{~mm}$ calcein-NaOH (pH 7.4). The mixture was sonicated to obtain a homogenous emulsion. The diethyl ether solvent was removed using a conventional rotary evaporator under reduced pressure at $25^{\circ} \mathrm{C}$. The resulting suspension of liposome was centrifuged and washed twice with fresh buffer A (10 $\mathrm{mm}$ phosphate buffer, containing $150 \mathrm{~mm} \mathrm{NaCl}$ ) to re- move untrapped calcein. The final liposome precipitate was re-suspended in $5 \mathrm{ml}$ buffer A. A $0.3 \mathrm{ml}$ aliquot of this suspension was diluted with $19.7 \mathrm{ml}$ of buffer $\mathrm{A}$, following which $400 \mu \mathrm{l}$ of this suspension was incubated at $30^{\circ} \mathrm{C}$ for $10 \mathrm{~min}$ in the presence of the NSAID under investigation. The release of calcein from liposomes (the amount of calcein outside the liposomes) was determined by measuring fluorescence intensity at $520 \mathrm{~nm}$ (excitation at $490 \mathrm{~nm}$ ), because the calcein fluoresces very weakly when at high concentrations (when calcein is trapped in liposomes) due to self-quenching.

Hemolysis in erythrocytes were monitored as described ${ }^{33,34)}$ with some modifications. Rat erythrocytes were washed twice with buffer A (5 mM HEPES/NaOH ( $\mathrm{pH} 7.4)$ and $150 \mathrm{~mm} \mathrm{NaCl}$ ) and then suspended in fresh buffer A at a final concentration of $0.5 \%$ hematocrit $\left(5 \times 10^{7}\right.$ cells $\left./ \mathrm{ml}\right)$. After incubation with NSAIDs for $10 \mathrm{~min}$ at $30^{\circ} \mathrm{C}$, hemolysis was estimated by measuring the absorbance at $520 \mathrm{~nm}$.

Statistical Analyses All values are expressed as the mean \pm S.E.M. The Tukey test or the Student's $t$-test for unpaired results was used to evaluate differences between more than three groups or between two groups, respectively.

\section{RESULTS AND DISCUSSION}

Necrosis- and Apoptosis-Inducing Activities of Loxoprofen and Loxoprofen-OH in Primary Culture of Gastric Mucosal Cells We previously reported that NSAIDs induce either necrosis or apoptosis depending on treatment conditions; short-term $(1 \mathrm{~h})$ treatment of primary cultures of guinea pig gastric mucosal cells with relatively high concentrations of NSAIDs $(2.5 \mathrm{~mm}$ for indomethacin and $0.2 \mathrm{~mm}$ for celecoxib) and long-term (16-24h) treatment of these cells with relatively low concentrations of NSAIDs (1 mM for indomethacin and $0.05 \mathrm{~mm}$ for celecoxib) induces necrosis and apoptosis, respectively. ${ }^{18,19,24)}$ Loxoprofen and loxoprofen$\mathrm{OH}$ were tested here for their ability to induce necrosis and apoptosis. Consistent with previous reports, ${ }^{18,19,24)}$ cell viability decreased in a dose-dependent manner when guinea pig gastric mucosal cells in primary culture were treated with indomethacin or celecoxib for $1 \mathrm{~h}$. In contrast, loxoprofen and loxoprofen-OH decreased cell viability to a much lesser extent under the same experimental conditions; cell viability of more than $60 \%$ was observed even with the highest concentration (20 mm) of loxoprofen and loxoprofen-OH (Fig. 1). We confirmed that cell death highlighted in Fig. 1 was medi-

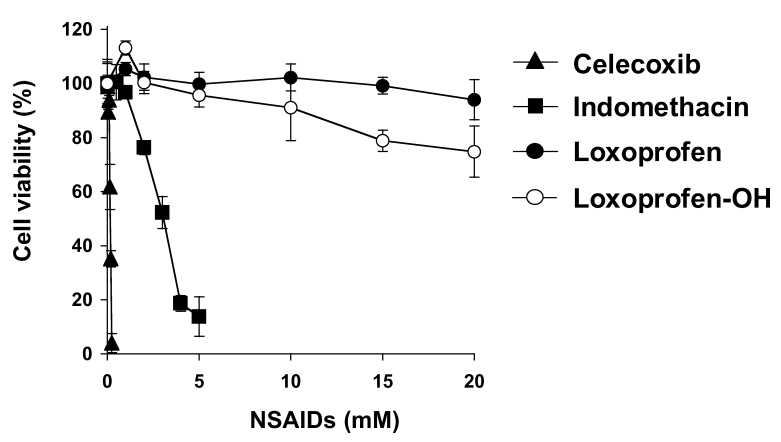

Fig. 1. Necrosis Induced by NSAIDs in Primary Culture of Gastric Mucosal Cells

Cultured guinea pig gastric mucosal cells were incubated with indicated concentrations of NSAIDs for $1 \mathrm{~h}$. Cell viability was determined by the MTT method. Values are mean \pm S.E.M. $(n=3)$. 
ated by necrosis given that no accompanying apoptotic DNA fragmentation or apoptotic chromatin condensation were evident (data not shown).

Similar results to the above were obtained when apoptosis was induced. Treatment of cells for $18 \mathrm{~h}$ with indomethacin or celecoxib decreased cell viability in a dose-dependent manner (Fig. 2A), which is also consistent with previous re- ports. ${ }^{18,19,24)}$ Loxoprofen and loxoprofen-OH showed very low activities for decreasing cell viability under these conditions (Fig. 2A). Because cell death as highlighted in Fig. 2 was accompanied by apoptotic DNA fragmentation and apoptotic chromatin condensation (Figs. 2B, C), it is most likely to have been mediated by apoptosis. Overall, the results in Figs. 1 and 2 show that loxoprofen and loxoprofen-
A

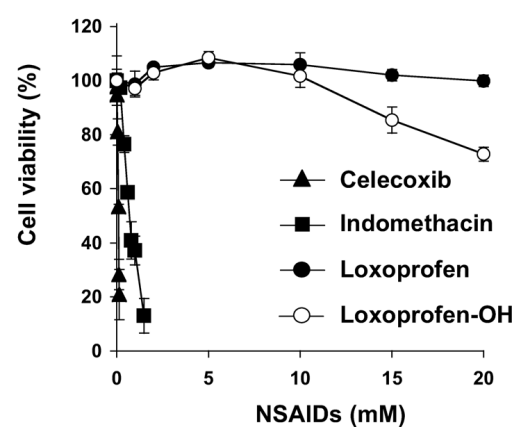

B

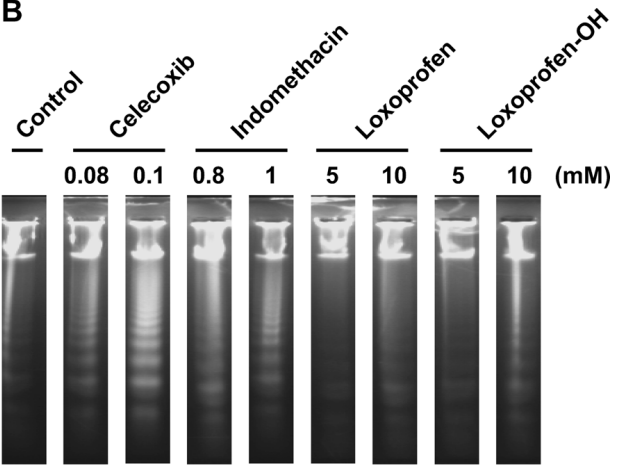

C
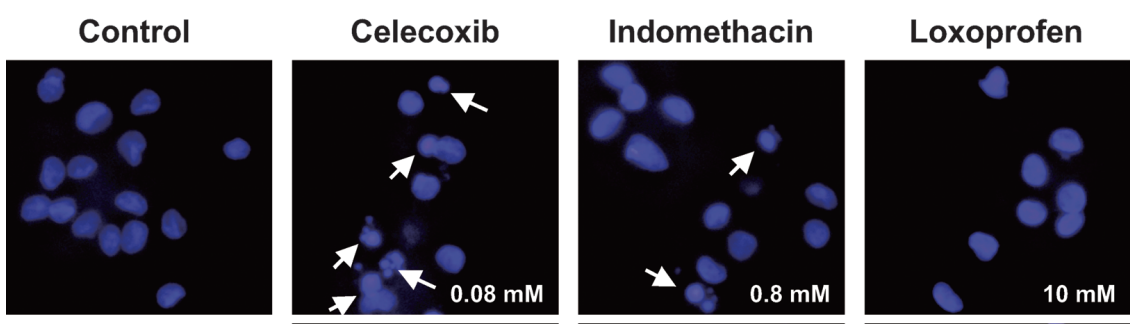

Loxoprofen-OH
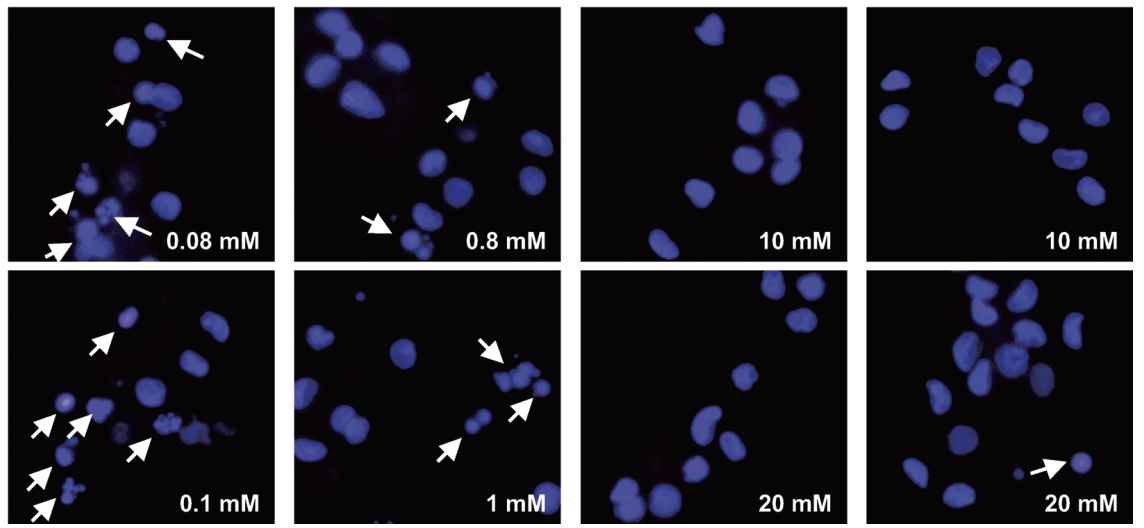

Fig. 2. Apoptosis Induced by NSAIDs in Primary Culture of Gastric Mucosal Cells

Cultured guinea pig gastric mucosal cells were incubated with indicated concentrations of NSAIDs for $18 \mathrm{~h}$. Cell viability was determined by the MTT method. Values are mean \pm S.E.M. $(n=3)($ A). Apoptotic DNA fragmentation (B) and chromatin condensation (C) were monitored as described in Materials and Methods.

A

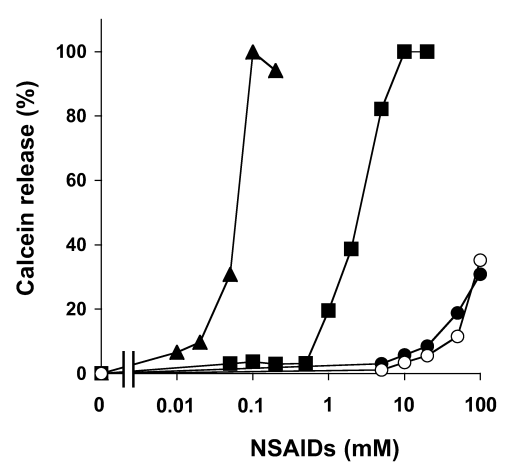

$\triangle$ Celecoxib
B

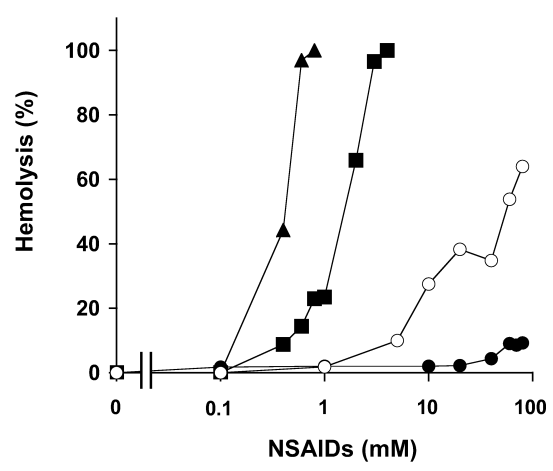

Loxoprofen $\quad-\mathrm{O}$ - Loxoprofen-OH

Fig. 3. Membrane Permeabilization by NSAIDs

Calcein-loaded liposomes were incubated for $10 \mathrm{~min}$ at $30^{\circ} \mathrm{C}$ with indicated concentrations of NSAIDs. The release of calcein from liposomes was determined by measuring fluorescence intensity. Melittin $(10 \mu \mathrm{M})$ was used to determine the $100 \%$ level of membrane permeabilization (A). Rat erythrocytes were incubated in the presence of each of NSAIDs for $10 \mathrm{~min}$ at $30^{\circ} \mathrm{C}$. Hemolysis was estimated by measuring the absorbance at $520 \mathrm{~nm}$ (B). 
$\mathrm{OH}$ induce necrosis and apoptosis to a lesser extent than do indomethacin and celecoxib. Furthermore, although the metabolic conversion of loxoprofen to loxoprofen-OH drastically increases the inhibitory activity on COX, this conversion does not seem to be so apparently associated with a similar increase in direct cytotoxicity.

Membrane Permeabilization Activities of Loxoprofen and Loxoprofen-OH The ability of loxoprofen and loxoprofen-OH to permeabilize the membranes of calcein-loaded liposomes was examined. Calcein fluoresces very weakly when at high concentrations due to self-quenching. Thus, the addition of membrane permeabilizing drugs to a medium containing calcein-loaded liposomes should cause an increase in fluorescence by releasing calcein trapped within the liposomes. ${ }^{18)}$ As shown in Fig. 3A, indomethacin and cele- coxib increased the calcein fluorescence in a dose-dependent manner, which is consistent with previous findings. ${ }^{18)}$ Loxoprofen and loxoprofen-OH also increased the calcein fluorescence, suggesting that they caused membrane permeabilization; however, as the concentrations of loxoprofen and loxoprofen-OH required for membrane permeabilization were much higher than those of indomethacin and celecoxib, their abilities to permeabilize membranes were thus very weak.

Measurement of hemolysis is a standard method for testing the membrane permeabilization activities of drugs. As shown in Fig. 3B, all of the tested NSAIDs caused hemolysis of erythrocytes. The relative potency of each NSAID for hemolysis was approximately similar to that for permeabilization of calcein-loaded liposomes. Celecoxib showed the most potent activity for hemolysis, followed by indomethacin and
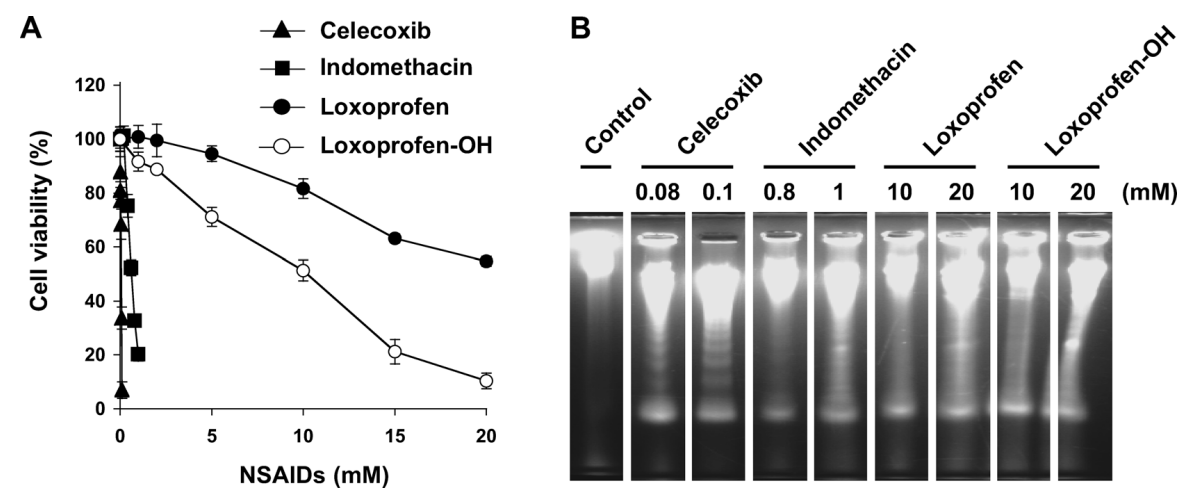

C
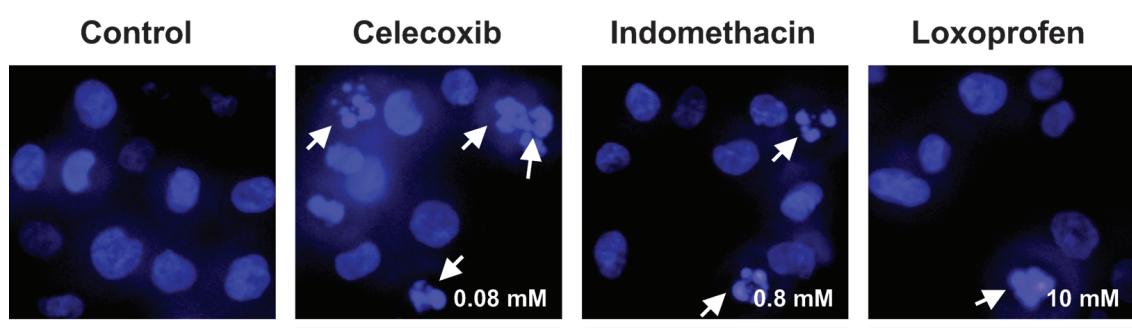

Loxoprofen-OH
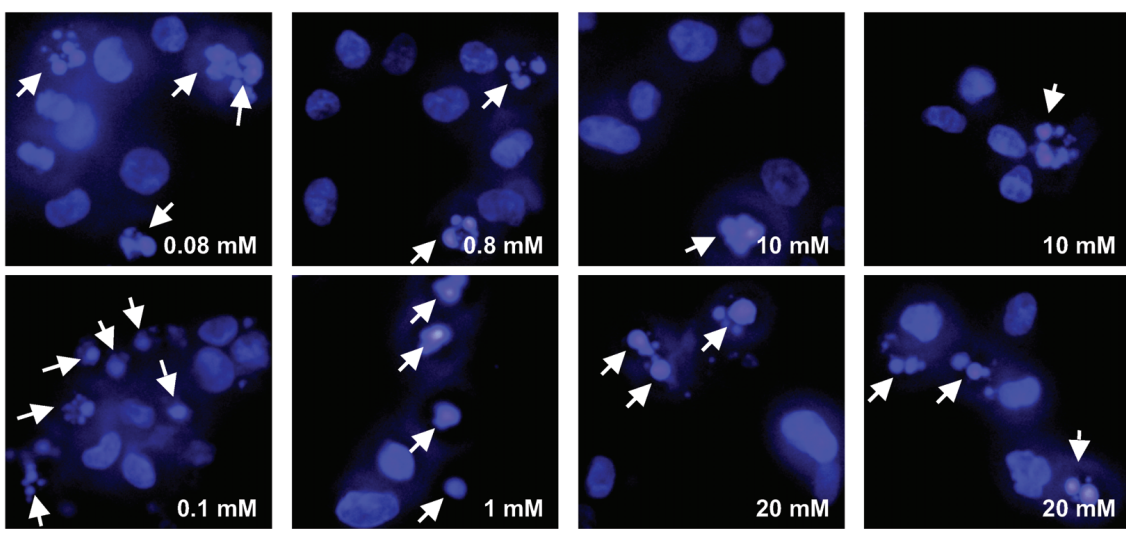

D

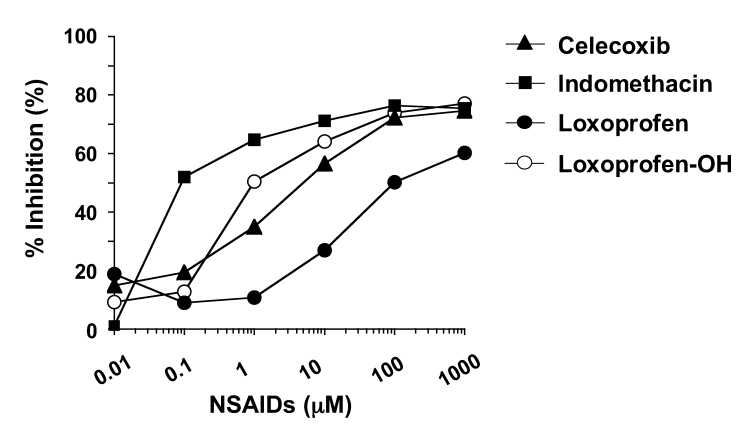

Fig. 4. Apoptosis Induced by NSAIDs in AGS Cells

AGS cells were incubated with indicated concentrations of NSAIDs for $24 \mathrm{~h}$ (A-C) or $4 \mathrm{~h}$ (D). Cell viability was determined by the MTT method. Values are mean \pm S.E.M. $(n=3)(\mathrm{A})$. Apoptotic DNA fragmentation (B) and chromatin condensation (C) were monitored as described in Materials and Methods. The arachidonic acid (50 $\mu \mathrm{M}$ at final) was added and cells were incubated for $15 \mathrm{~min}$. The amount of $\mathrm{PGE}_{2}$ in culture medium was determined by EIA and results were shown as inhibition of COX synthesis (D). 
both loxoprofen and loxoprofen-OH showed weak activity for hemolysis (Fig. 3B). Loxoprofen showed lower permeabilization activity than loxoprofen- $\mathrm{OH}$ on the hemolysis assay (Fig. 3B).

The results shown in Fig. 3 suggest that the low direct cytotoxicity of loxoprofen and loxoprofen-OH on gastric mucosal cells is due to their low membrane permeabilizing effects.

Cytotoxic Effects of Loxoprofen and Loxoprofen-OH on Gastric Cancer Cells In addition to their anti-inflammatory effects, recent epidemiological studies have revealed that prolonged NSAID use reduces the risk of cancer, while preclinical and clinical studies have indicated that some NSAIDs are effective in the treatment and prevention of cancer. $^{35)}$ The anti-tumorigenic activity of NSAIDs is believed to involve various mechanisms, including induction of apoptosis. ${ }^{36,37)}$ Thus, it is important to examine the apoptosis-inducing ability of loxoprofen in cancer cells and we here used cultured AGS cells for this purpose.

As shown in Fig. 4A, each NSAID induced apoptosis in a dose dependent manner in AGS cells and loxoprofen and loxoprofen-OH showed less activity for inducing apoptosis than indomethacin and celecoxib. We confirmed that cell death observed in Fig. 4A is mediated by apoptosis, because it was accompanied by apoptotic DNA fragmentation and apoptotic chromatin condensation (Figs. 4B, C). Comparing to data in primary culture of gastric mucosal cells (Fig. 2), loxoprofen and loxoprofen-OH induced apoptosis more potently in AGS cells. The $\mathrm{ED}_{70}$ values of NSAIDs for apoptosis (concentrations of NSAIDs required for $70 \%$ cell viability by apoptosis) of loxoprofen and loxoprofen-OH were lower in AGS cells than in primary culture of gastric mucosal cells (Table 1). On the other hand, the $\mathrm{ED}_{70}$ values for apoptosis of indomethacin and celecoxib were nearly indistinguishable between AGS cells and primary culture of gastric mucosal cells (Table 1). Although the underlying mechanism is unknown at present, this character of loxoprofen and loxoprofen-OH may be clinically beneficial for their application as anti-tumor drugs.

We also examined the effect of NSAIDs on the COX activity in cultured AGS cells. As shown in Fig. 4D, each of all NSAIDs tested decreased the amount of $\mathrm{PGE}_{2}$ in the culture medium, in other words, inhibited COX activity in a dose dependent manner.

In summary, we show here that loxoprofen and loxoprofen-OH have a very low level of direct cytotoxicity on gastric mucosal cells in vitro. As described above, it is well known that loxoprofen is clinically safe on gastric mucosa compared to other NSAIDs such as indomethacin. ${ }^{25,26)}$ We propose here that the low direct cytotoxicity of loxoprofen make it less harmful on the gastric mucosa for clinical use.

As described above, we have suggested that both COX inhibition (decrease in gastric level of $\mathrm{PGE}_{2}$ ) and gastric mucosal cell death are required for the formation of NSAID-induced gastric lesions in vivo (Fig. 5). ${ }^{20,24)}$ Based on this idea, either NSAIDs without decreasing gastric level of $\mathrm{PGE}_{2}$ or NSAIDs with lower cytotoxic effect should be safe NSAIDs on gastric mucosa. In other words, NSAIDs that have high cytotoxic effect on gastric mucosa and high ability to inhibit COX-1 expressed in gastric mucosa should have high risk for formation of gastric lesions. Indomethacin belongs to this
Table 1. NSAID Concentrations Required for Apoptosis

\begin{tabular}{lcc}
\hline \hline \multicolumn{1}{c}{ NSAIDs } & Primary cell $(\mathrm{mm})$ & AGS cell $(\mathrm{mm})$ \\
\hline Celecoxib & 0.06 & 0.05 \\
Indomethacin & 0.42 & 0.40 \\
Loxoprofen & $<20$ & 11.8 \\
Loxoprofen-OH & 19.1 & 4.3
\end{tabular}

$\mathrm{ED}_{70}$ values of NSAIDs for apoptosis (concentrations of NSAIDs required for $70 \%$ cell viability by apoptosis) in primary culture of gastric mucosal cells and in AGS cells were calculated based on results provided in Fig. 1 and Fig. 4, respectively.

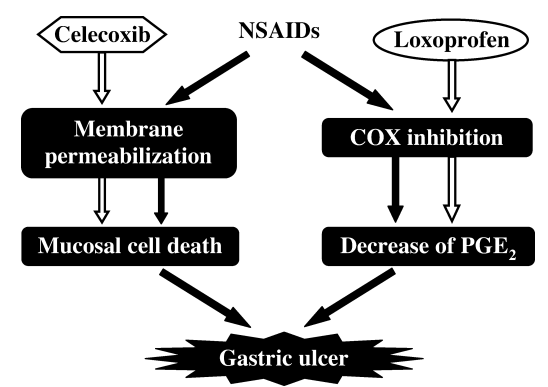

Fig. 5. A Model for Production of Gastric Lesions by NSAIDs

We have proposed that both COX inhibition (decrease in gastric level of $\mathrm{PGE}_{2}$ ) and gastric mucosal cell death are required for the formation of NSAID-induced gastric lesions in vivo. ${ }^{20,24)}$ This idea can explain the safety of selective COX-2 inhibitors, such as celecoxib, and loxoprofen on gastric mucosa, because they have lower ability to decrease gastric level of $\mathrm{PGE}_{2}$ and to induce gastric mucosal cell death, respectively.

type of NSAIDs and has relatively high risk for formation of gastric lesions clinically. Selective COX-2 inhibitors are relatively safe for gastric mucosa, because they have lower ability to inhibit COX-1 expressed in gastric mucosa, resulting in maintenance of gastric level of $\mathrm{PGE}_{2}$. However, potential risk for cardiovascular thrombotic events is concern. Thus, we propose that NSAIDs with lower cytotoxic effect likely to be therapeutically beneficial NSAIDs in terms of gastrointestinal and cardiovascular safety. We are now synthesizing derivatives of loxoprofen to obtain more safe NSAIDs on gastric mucosa.

Acknowledgements This work was supported by Grants-in-Aid for Scientific Research from the Ministry of Health, Labour, and Welfare of Japan, Grants-in-Aid for Scientific Research from the Ministry of Education, Culture, Sports, Science and Technology of Japan, and Grants-in-Aid of the Japan Science and Technology Agency.

\section{REFERENCES}

1) Smalley W. E., Ray W. A., Daugherty J. R., Griffin M. R., Am. J. Epidemiol., 141, 539-545 (1995).

2) Hawkey C. J., Gastroenterology, 119, 521-535 (2000)

3) Barrier C. H., Hirschowitz B. I., Arthritis Rheum., 32, 926-932 (1989).

4) Fries J. F., Miller S. R., Spitz P. W., Williams C. A., Hubert H. B., Bloch D. A., Gastroenterology, 96, 647-655 (1989).

5) Kujubu D. A., Fletcher B. S., Varnum B. C., Lim R. W., Herschman H. R., J. Biol. Chem., 266, 12866-12872 (1991).

6) Xie W. L., Chipman J. G., Robertson D. L., Erikson R. L., Simmons D. L., Proc. Natl. Acad. Sci. U.S.A., 88, 2692-2696 (1991).

7) Silverstein F. E., Faich G., Goldstein J. L., Simon L. S., Pincus T., Whelton A., Makuch R., Eisen G., Agrawal N. M., Stenson W. F., Burr A. M., Zhao W. W., Kent J. D., Lefkowith J. B., Verburg K. M., Geis G. S., JAMA, 284, 1247-1255 (2000).

8) Bombardier C., Laine L., Reicin A., Shapiro D., Burgos V. R., Davis 
B., Day R., Ferraz M. B., Hawkey C. J., Hochberg M. C., Kvien T. K., Schnitzer T. J., N. Engl. J. Med., 343, 1520-1528, (2000).

9) FitzGerald G. A., Patrono C., N. Engl. J. Med., 345, 433-442 (2001).

10) Mukherjee D., Nissen S. E., Topol E. J., JAMA, 286, 954-959 (2001).

11) Mukherjee D., Biochem. Pharmacol., 63, 817-821 (2002).

12) McAdam B. F., Catella L. F., Mardini I. A., Kapoor S., Lawson J. A., FitzGerald G. A., Proc. Natl. Acad. Sci. U.S.A., 96, 272-277 (1999).

13) Catella L. F., McAdam B., Morrison B. W., Kapoor S., Kujubu D., Antes L., Lasseter K. C., Quan H., Gertz B. J., FitzGerald G. A., J. Pharmacol. Exp. Ther, 289, 735-741 (1999).

14) Belton O., Byrne D., Kearney D., Leahy A., Fitzgerald D. J., Circulation, 102, 840-845 (2000).

15) Lichtenberger L. M., Biochem. Pharmacol., 61, 631-637 (2001).

16) Tanaka K., Tomisato W., Hoshino T., Ishihara T., Namba T., Aburaya M., Katsu T., Suzuki K., Tsutsumi S., Mizushima T., J. Biol. Chem., 280, 31059-31067 (2005).

17) Tsutsumi S., Gotoh T., Tomisato W., Mima S., Hoshino T., Hwang H. J., Takenaka H., Tsuchiya T., Mori M., Mizushima T., Cell Death Differ. 11, 1009-1016 (2004).

18) Tomisato W., Tanaka K., Katsu T., Kakuta H., Sasaki K., Tsutsumi S., Hoshino T., Aburaya M., Li D., Tsuchiya T., Suzuki K., Yokomizo K., Mizushima T., Biochem. Biophys. Res. Commun., 323, 1032-1039 (2004).

19) Tomisato W., Tsutsumi S., Rokutan K., Tsuchiya T., Mizushima T., Am. J. Physiol. Gastrointest. Liver Physiol., 281, G1092-1100 (2001).

20) Aburaya M., Tanaka K., Hoshino T., Tsutsumi S., Suzuki K., Makise M., Akagi R., Mizushima T., J. Biol. Chem., 281, 33422-33432 (2006).

21) Tsutsumi S., Namba T., Tanaka K. I., Arai Y., Ishihara T., Aburaya M., Mima S., Hoshino T., Mizushima T., Oncogene, 25, 1018-1029 (2006).

22) Namba T., Hoshino T., Tanaka K., Tsutsumi S., Ishihara T., Mima S.,
Suzuki K., Ogawa S., Mizushima T., Mol. Pharmacol., 71, 860—870 (2007).

23) Ishihara T., Hoshino T., Namba T., Tanaka K., Mizushima T., Biochem. Biophys. Res. Commun., 356, $711-717$ (2007).

24) Tomisato W., Tsutsumi S., Hoshino T., Hwang H. J., Mio M., Tsuchiya T., Mizushima T., Biochem. Pharmacol., 67, 575-585 (2004).

25) Misaka E., Yamaguchi T., Iizuka Y., Kamoshida K., Kojima T., Kobayashi K., Endo Y., Misawa Y., Lobayashi S., Tanaka K., Pharmacometrics, 21, 753-771 (1981).

26) Kawano S., Tsuji S., Hayashi N., Takei Y., Nagano K., Fusamoto H., Kamada T., J. Gastroenterol. Hepatol., 10, 81—85 (1995).

27) Sugimoto M., Kojima T., Asami M., Iizuka Y., Matsuda K., Biochem. Pharmacol., 42, 2363-2368 (1991).

28) Hirakawa T., Rokutan K., Nikawa T., Kishi K., Gastroenterology, 111, 345-357 (1996).

29) Tomisato W., Takahashi N., Komoto C., Rokutan K., Tsuchiya T., Mizushima T., Dig. Dis. Sci., 45, 1674-1679 (2000).

30) Tomisato W., Hoshino T., Tsutsumi S., Tsuchiya T., Mizushima T., Dig. Dis. Sci., 47, 2125-2133 (2002).

31) Tsutsumi S., Tomisato W., Takano T., Rokutan K., Tsuchiya T., Mizushima T., Biochim. Biophys. Acta, 1589, 168-180 (2002).

32) Ushijima H., Tanaka K., Takeda M., Katsu T., Mima S., Mizushima T., Mol. Pharmacol., 68, 1156-1161 (2005).

33) Katsu T., Kuroko M., Morikawa T., Sanchika K., Yamanaka H., Shinoda S., Fujita Y., Biochim. Biophys. Acta, 1027, 185-190 (1990).

34) Katsu T., Kobayashi H., Hirota T., Fujita Y., Sato K., Nagai U., Biochim. Biophys. Acta, 899, 159-170 (1987).

35) Wang W. H., Huang J. Q., Zheng G. F., Lam S. K., Karlberg J., Wong B. C., J. Natl. Cancer. Inst., 95, 1784-1791 (2003).

36) Gupta R. A., Dubois R. N., Nat. Rev. Cancer, 1, 11-21 (2001).

37) Kismet K., Akay M. T., Abbasoglu O., Ercan A., Cancer Detect. Prev., 28, 127-142 (2004). 